\title{
Evaluation of retinectomy in the treatment of severe proliferative vitreoretinopathy
}

\author{
Thaís Sousa Mendes ${ }^{1 *}$, André Marcelo Vieira Gomes ${ }^{1,2}$, Bruno Saraiva Rocha ${ }^{1}$, Hélcio Valério Passos Junior ${ }^{1}$ \\ and Suel Abujamra ${ }^{1,2}$
}

\begin{abstract}
Background: To evaluate the postoperative results and efficacy of retinectomy in the treatment of severe proliferative vitreoretinopathy (PVR).

Methods: The study involved 38 individuals with rhegmatogenous retinal detachment initially diagnosed with PVR grade C3 who had undergone pars plana vitrectomy combined with scleral buckle and silicone oil as a tamponade. A standard three-port pars plana vitrectomy was performed, and the extension of performing a retinectomy was decided during the procedure. The patients were followed for a minimum of 6 months after the last surgical procedure. Reoperation, postoperative hypotony and final reattachment rates were evaluated. Statistical analysis was performed with an Exact Fisher's test.
\end{abstract}

Results: The mean preoperative visual acuity was $>1.3 \log M A R$. The postoperative visual acuity improved and ranged from 1.3 to $0.7 \log$ MAR $(p<0.63)$. The preoperative intraocular pressure was $10.2 \mathrm{mmHg}$ and postoperatively was $11.6 \mathrm{mmHg}$. Postoperative hypotony was observed in $15.8 \%$ of the cases. The reoperation rate after the first procedure was $63.2 \%$. A total of $44.7 \%$ of the patients needed a retinectomy greater than $270^{\circ}$ for a final anatomical success. The final retinal reattachment rate was $94.7 \%$.

Conclusions: Retinectomy can be an effective surgical procedure in the treatment of severe PVR, and it may increase the final reattachment rate.

Keywords: Retinal detachment, Retinectomy, Severe proliferative vitreoretinopathy

\section{Background}

Proliferative vitreoretinopathy (PVR) is the most common cause of failure in the management of rhegmatogenous retinal detachment (RRD). PVR occurs in 5-10\% of retinal detachment (RD) surgeries, and it comprises glial and retinal pigment epithelium cells that migrate and generate membranes usually on the lower retina as a result of gravity. Contraction of these membranes can cause new retinal tears, macular pucker, recurrent RD

\footnotetext{
*Correspondence: thaismendesoft@gmail.com

${ }^{1}$ Department of Ophthalmology, Suel Abujamra Institute, 693 Tamandare Street, 9th floor, Sao Paulo, SP 01531-000, Brazil

Full list of author information is available at the end of the article
}

and hypotony. PVR categories are grades A, B, and C1C5 [1-3].

The rate of anatomic success in RRD surgery can reach 80-90\% due to current advanced surgical techniques, especially in cases of RD involving mild PVR (grades AC1). However, in cases of severe PVR (grades C2-C5), the prognosis is significantly poorer, considering anatomical and visual outcomes [1-4].

In the past, there has been controversy regarding the use of silicone oil versus gas as a tamponade in cases of RD associated with severe PVR. The Silicone Study (1992) concluded that perfluoropropane (C3F8) or silicone oil is more effective than SF6 in the treatment of PVR cases [5]. The use of pharmacological agents as adjuvant therapy in RD surgery has been described. 
Studies have described the use of daunomycin, 5-fluorouacil and heparin as adjuvant therapy. However, these studies reported that these drugs failed to improve final anatomic results $[2,6,7]$.

In 1979, Machemer first described retinectomy as a treatment for complex RRD. Since that study, many authors have reported relaxing retinectomy as a valuable technique in the surgical management of severe PVR to achieve a high rate of anatomical success. Additionally, recent studies have suggested silicone oil as a superior tamponade compared to gas in eyes with PVR $[4,8]$.

Our study aimed to evaluate the efficacy of retinectomy in the surgical treatment of RRD associated with severe PVR and its effect on the reoperation rate and final retinal reattachment.

\section{Methods}

A retrospective study was conducted in 38 eyes of 38 patients with RRD initially diagnosed with PVR grade C3 who had undergone pars plana vitrectomy (PPV) combined with scleral buckle and silicone oil as a tamponade from June 2006 to June 2010. The study excluded eyes with previous vitrectomy for RRD, non-RRD and trauma.

The surgical technique included $360^{\circ}$ peritomy, scleral buckle, and three-port incision (scleretomies) combined with a 23-gauge vitrectomy, which was performed by one experienced retinal surgeon (AG). Retinectomy extension was performed according to the surgeon's decision at the time of surgery based on retinal shortening $\left(180^{\circ}, 270^{\circ}\right.$ or $\left.360^{\circ}\right)$. For all cases, 5000 centistokes silicone oil was used as a tamponade and a scleral buckle was not placed if a $360^{\circ}$ shortening was made necessary during vitrectomy.

The postoperative follow-up was performed at 1 day, 1 week, 15, 30, 60, 90 and 6 months after the last surgical procedure was performed. Postoperative hypotony was defined as intraocular pressure ranging from 0 to $5 \mathrm{mmHg}$. Patients who did not complete 6 months of follow-up were excluded. Silicone oil was removed after a minimum of 3 months in patients with no signs of recurrent PVR or persistent RD.

A Fisher's test was used to verify the association between the rate of reoperation and retinectomy performed. The postoperative average best-corrected visual acuity (BCVA) was analyzed with a Mann-Whitney test because of non-measurable values in LogMAR. A $p$ value $<0.05$ was considered statistically significant.

\section{Results}

Patients were $62.9 \pm 15.3$ years of age and $52.5 \%$ were male. Regarding lens status, $78.9 \%$ of patients were phakic, $15.8 \%$ were pseudophakic and $5.3 \%$ were aphakic. The average preoperative IOP was $10.2 \pm 4.1 \mathrm{mmHg}$ and postoperative IOP was $11.6 \pm 3.8 \mathrm{~mm} \mathrm{Hg}$.
The average preoperative BCVA was greater than 1.3 LogMAR ( $<20 / 400$ Snellen Equivalent). All eyes achieved improvement to a final BCVA ranging from 1.3 to 0.7 LogMAR. Postoperative hypotony was determined in $15.8 \%$ of the patients. Only one eye developed neovascular glaucoma (Table 1 ).

After the first procedure, $63.2 \%$ of eyes needed a second surgery, including enlargement of the retinectomy from $180^{\circ}$ to $270^{\circ}(\mathrm{n}=11)$ or from $270^{\circ}$ to $360^{\circ}$ $(\mathrm{n}=1)$, silicone oil removal $(\mathrm{n}=10)$ and standard intraocular lens fixation $(n=2)$. A total of four eyes needed a third surgical procedure, including enlargement of the retinectomy from $270^{\circ}$ to $360^{\circ}$. A final reattachment was observed in $94.7 \%$ of the patients. Regarding extension of the retinectomy, $44.7 \%$ eyes underwent retinectomy greater than $270^{\circ}$ after the first surgery (Table 1).

There was an association between retinectomy extension and postoperative visual acuity. A total of $87 \%$ $(n=33)$ of the eyes had better or stabilized postoperative VA compared to preoperative VA. Regarding hypotony, there was no association between the hypotony rate and retinectomy extension (Tables 2, 3, 4). No patients needed a scleral buckle removal.

\section{Discussion}

Proliferative vitreoretinopathy remains the primary cause of unsuccessful RRD surgery. Relaxing retinectomies are mandatory when a complete relief of retinal traction is not possible, even after membrane removal. Previous

Table 1 Patient demographics, retinectomy extension and postoperative complications

\begin{tabular}{|c|c|c|}
\hline & $\mathbf{N}$ & Percentage (\%) \\
\hline Age & $62.9( \pm 15.3)$ & \\
\hline \multicolumn{3}{|l|}{ Gender } \\
\hline Female & 20 & 52.5 \\
\hline Male & 18 & 47.5 \\
\hline \multicolumn{3}{|l|}{ Lens status } \\
\hline Phakic & 30 & 78.9 \\
\hline Pseudophakic & 6 & 15.8 \\
\hline Aphakic & 2 & 5.3 \\
\hline \multicolumn{3}{|l|}{$\mathrm{IOP}(\mathrm{mmHg})$} \\
\hline Preoperative & $10.2( \pm 4.1)$ & \\
\hline Postoperative & $11.6( \pm 3.8)$ & \\
\hline \multicolumn{3}{|l|}{ Retinectomy extension } \\
\hline $180^{\circ}$ & 21 & 55.3 \\
\hline $270^{\circ}$ & 7 & 18.4 \\
\hline $360^{\circ}$ & 10 & 26.3 \\
\hline Neovascular glaucoma & 1 & 2.6 \\
\hline Postoperative hypotony & 6 & 15.8 \\
\hline
\end{tabular}


Table 2 Preoperative and postoperative best-corrected visual acuity

\begin{tabular}{|c|c|c|c|c|c|}
\hline \multicolumn{6}{|l|}{ BCVA } \\
\hline \multirow[t]{2}{*}{ LogMAR } & \multirow[t]{2}{*}{ Snellen } & \multicolumn{2}{|c|}{ Preoperative } & \multicolumn{2}{|c|}{ Postoperative } \\
\hline & & $\mathbf{N}$ & Percentage (\%) & $\mathrm{N}$ & Percentage (\%) \\
\hline 0.7 & 20/100 & 0 & 0 & 10 & 26.3 \\
\hline 1 & $20 / 200$ & 3 & 7.9 & 11 & 28.9 \\
\hline 1.3 & $20 / 400$ & 2 & 5.3 & 0 & 0 \\
\hline$>1.3-1.6$ & $<20 / 400-5 / 400$ & 2 & 5.3 & 6 & 15.8 \\
\hline 1.6 & $5 / 400$ & 26 & 68.4 & 3 & 7.9 \\
\hline$>1.6$ & $<5 / 400$ & 5 & 13.2 & 8 & 21.1 \\
\hline
\end{tabular}

Table 3 Final best corrected visual acuity and retinectomy extension

\begin{tabular}{lllll}
\hline & \multicolumn{3}{l}{ Retinectomy extension } & Total \\
\cline { 2 - 3 } & $\mathbf{3 6 0 ^ { \circ }}$ & $\mathbf{2 7 0}^{\circ}$ & $\mathbf{1 8 0}^{\circ}$ & \\
\hline Change in BCVA & & 3 & 2 & 5 \\
Worsening & 0 & 4 & 19 & 33 \\
Better or no change & 10 & 7 & 21 & 38 \\
Total & 10 & &
\end{tabular}

${ }^{*} p$ value $=0.049$

Table 4 Hypotony and retinectomy extension

\begin{tabular}{cccc}
\hline & \multicolumn{2}{c}{ Hypotony } & Total \\
\cline { 2 - 3 } & Yes & No & \\
\hline $\begin{array}{lll}\text { Retinectomy extension } \\
360^{\circ}\end{array}$ & 9 & 10 \\
$270^{\circ}$ & 1 & 4 & 7 \\
$180^{\circ}$ & 3 & 19 & 21 \\
Total & 2 & 32 & 38 \\
\hline
\end{tabular}

${ }^{*} p$ value $=0.13$

studies reported recurrent $\mathrm{RD}$ after $180^{\circ}-360^{\circ}$ retinectomies from 17 to $48 \%$. Our study found a higher rate of recurrent RD; however, most of the studies excluded eyes with PVR greater than C2 $[9,10]$.

Patients with severe PVR C3 who undergo retinectomy are more likely to develop postoperative PVR because of retinal pigment epithelium exposure, proliferation and migration of inflammatory cells on the retinal surface [2, 3]. In our study, all patients were classified as PVR greater than $\mathrm{C} 2$. This finding may explain the higher reoperation rate after the first procedure. However, the final reattachment rate of $94.7 \%$ was greater than reports in the literature for severe PVR cases $[8,9,11]$.
Postoperative hypotony is a common complication after large retinectomy and previous studies have reported a $15-40 \%$ rate in eyes that underwent a $360^{\circ}$ retinectomy [10-13]. Additionally, Teke et al. [9] reported $1.7 \%$ phthisical eyes. We report a $15.8 \%$ postoperative hypotony rate, but no patients developed phthisis bulbi in our study. This finding may be explained by our choice of silicone oil as a tamponade. Several authors believe that silicone oil may prevent hypotony and phthisis after vitrectomy $[10-12,14]$.

Our study has several limitations. This research is a retrospective study with a small number of patients. Additionally, we did not compare our patients with a control group in which retinectomy was not performed during the first surgical procedure. However, to the best of our knowledge, there are few studies in the literature evaluating the efficacy of retinectomy in eyes with PVR grade C3. Most studies have included PVR grade $\mathrm{C} 1-\mathrm{C} 2$ only $[8,9,11]$. A total of $44.7 \%$ of the patients needed a retinectomy greater than $270^{\circ}$ since the first surgery; nevertheless, most of them had an improved or stabilized final vision compared to preoperative VA. In the literature, only a small number of patients achieved ambulatory vision after a large retinectomy $[10,11]$.

\section{Conclusions}

Proliferative vitreoretinopathy is still a major cause of failure of RRD surgery, and occasionally, multiple procedures are required when reattachment is not obtained $[2,3,15]$. Retinectomy may result in a higher anatomical success rate for severe PVR cases by relaxing the shortened retina and may not be related to worse results concerning final visual acuity or hypotony.

\section{Authors' contributions}

TSM participated in the study design, data collection and analyses and drafted the manuscript. AMVG participated in the study design and coordination of the study. BSR participated in data collection and statistical analysis. HVPJ participated in data collection. SA participated in study coordination. All authors read and approved the final manuscript.

\section{Author details}

'Department of Ophthalmology, Suel Abujamra Institute, 693 Tamandare Street, 9th floor, Sao Paulo, SP 01531-000, Brazil. ${ }^{2}$ Department of Ophthalmology, University of Sao Paulo, Sao Paulo, SP 05403-900, Brazil.

Compliance with ethical guidelines

\section{Competing interests}

The authors declare that they have no competing interests.

Received: 27 March 2015 Accepted: 7 September 2015

Published online: 08 October 2015

\section{References}

1. Machemer R, McCuen B. An updated classification of retinal detachment with proliferative vitreoretinopathy. Am J Ophthalmol. 1991;112:159-65. 
2. Charteris DG, Sethi CS, Lewis GP, Fisher SK. Proliferative vitreoretinopathy-developments in adjunctive treatment and retinal pathology. Eye. 2002;16:369-74

3. Furino C, Micelli FT, Boscia F, Cardascia N, Recchimurzo N, Sborgia C. Triamcinolone-assisted pars plana vitrectomy for proliferative vitreoretinopathy. Retina. 2003;23:771-6.

4. Tsui I, Schubert HD. Retinotomy and silicone oil for detachments complicated by anterior inferior proliferative vitreoretinopathy. Br J Ophthalmol. 2009:93:1228-33.

5. Abrams GW, Azen SP, McCuen BW 2nd, Flynn HW Jr, Lai MY, Ryan SJ. Vitrectomy with silicone oil or long-acting gas in eyes with severe proliferative vitreoretinopathy: results of additional and long-term follow-up. Silicone Study report 11. Arch Ophthalmol. 1997;115:335-44.

6. Asaria RH, Kon CH, Bunce C, Charteris DG, Wong D, Khaw PT, et al. Adjuvant 5-fluorouracil and heparin prevents proliferative vitreoretinopathy: results from a randomized, double-blind, controlled clinical trial. Ophthalmology. 2001;108:1179-83.

7. Wiedemann P, Hilgers RD, Bauer P, Heimann K. Adjunctive daunorubicin in treatment of proliferative vitreoretinopathy: results of a multicenter clinical trial. Daunomycin Study Group. Am J Ophthalmol. 1998;126:550-9.

8. Teke MY, Balikoglu-Yilmaz M, Yuksekkaya P, Citirik M, Elgin U, Kose T, et al. Surgical outcomes and incidence of retinal redetachment in cases with complicated retinal detachment after silicone oil removal: univariate and multiple risk factors analysis. Retina (Philadelphia, Pa). 2014;34:1926-38.
9. Sato T, Emi K, Bando H, Ikeda T. Retrospective comparison of 25-gauge vitrectomy for repair of proliferative vitreoretinopathy with or without anterior proliferation. Graefes Arch Clin Exp Ophthalmol. 2014;252(12):1895-902.

10. Kolomeyer AM, Grigorian RA, Mostafavi D, Bhagat N, Zarbin MA. $360^{\circ}$ retinectomy for the treatment of complex retinal detachment. Retina (Philadelphia, Pa). 2011;31:266-74.

11. Garnier S, Rahmi A, Grasswil C, Kodjikian L. Three hundred and sixty degree retinotomy for retinal detachments with severe proliferative vitreoretinopathy. Graefes Arch Clin Exp Ophthalmol. 2013;251:2081-5.

12. de Silva DJ, Kwan A, Bunce C, Bainbridge J. Predicting visual outcome following retinectomy for retinal detachment. Br J Ophthalmol. 2008:92:954-8

13. Zarbin MA, Michels RG, Green WR. Dissection of epiciliary tissue to treat chronic hypotony after surgery for retinal detachment with proliferative vitreoretinopathy. Retina. 1991;11(2):208-13.

14. Shalaby KA-G. Relaxing retinotomies and retinectomies in the management of retinal detachment with severe proliferative vitreoretinopathy (PVR). Clin Ophthalmol. 2010;4:1107-14.

15. Enaida H, Hata Y, Ueni A, Nakamura T, Hisatomi T, Miyazaki M, et al. Possible benefits of triamcinolone-assisted pars plana vitrectomy for retinal diseases. Retina. 2003;23:764-70.

\section{Submit your next manuscript to BioMed Central and take full advantage of:}

- Convenient online submission

- Thorough peer review

- No space constraints or color figure charges

- Immediate publication on acceptance

- Inclusion in PubMed, CAS, Scopus and Google Scholar

- Research which is freely available for redistribution

Submit your manuscript at

www.biomedcentral.com/submit

C Biomed Central 